\title{
$\underline{U} \underline{N} \underline{C} \underline{L} \underline{A} \underline{S} \underline{S} \underline{I} \underline{F} \underline{I} \underline{E} \underline{D}$ \\ $\underline{\mathrm{ISC}-707}$
}

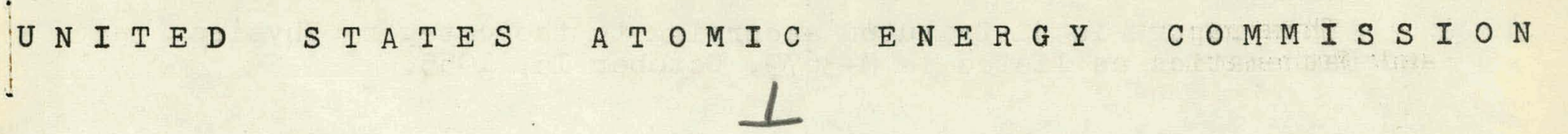

\section{SEMI-ANNUAL SUMMARY RESEARCH REPORT IN PHYSICS \\ For July through December, 1955}

\section{by}

Ames Laboratory Staff

March 8, 1956

Ames Laboratory

at

Iowa State College

F. H. Spedding, Director

Contract $\mathrm{W}-7405$ eng-82

$\underline{U} \underline{N} \underline{C} \underline{L} \underline{A} \underline{S} \underline{S} \underline{I} \underline{F} \underline{I} \underline{E} \underline{D}$ 


\section{DISCLAIMER}

This report was prepared as an account of work sponsored by an agency of the United States Government. Neither the United States Government nor any agency Thereof, nor any of their employees, makes any warranty, express or implied, or assumes any legal liability or responsibility for the accuracy, completeness, or usefulness of any information, apparatus, product, or process disclosed, or represents that its use would not infringe privately owned rights. Reference herein to any specific commercial product, process, or service by trade name, trademark, manufacturer, or otherwise does not necessarily constitute or imply its endorsement, recommendation, or favoring by the United States Government or any agency thereof. The views and opinions of authors expressed herein do not necessarily state or reflect those of the United States Government or any agency thereof. 


\section{DISCLAIMER}

Portions of this document may be illegible in electronic image products. Images are produced from the best available original document. 
This report is distributed according to the category Physics and Mathematics as 11sted in M-3679, October 15, 1955.

This report was prepared as a scientific account of Government-sponsored work. Neither the United States, nor the Commission, nor any person or contractor acting on behalf of the Commission, makes any warranty or representation, express or implied, with respect to the accuracy, completeness or usefulness of the information contained in this report, or that the use of any information, apparatus, method or process disclosed in this report may not infringe privately owned rights. The Commission assumes no liability with respect to the use of, or for damages resulting from the use of any information, apparatus, method or process disclosed in this report.

Printed in USA. Price 25 cents. Available from the

Office of Technical Services U. S. Department of Commerce Washington $25, D$. C. 
Theoretical Physics

1. Magnetic properties of dysprosium.............

Experimental Physics

1. Nuclear Studies. . . . . . . . . . . . 7

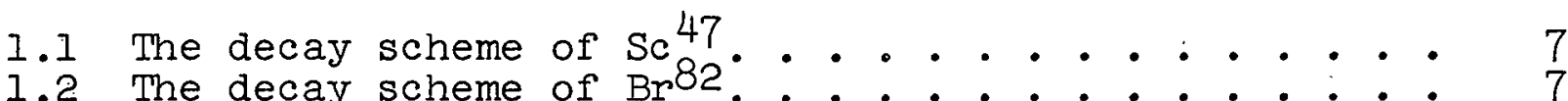

1.2 Some measurements of beta-gamma directional $\cdot \cdots \cdot$.

correlations. . . . . . . . . . . . . 99 9

1.4 Small order effects of beta spectra......... 10

1.5 Ionization yields for fission fragments....... 10

1.6 Excitation of 1somers by high energy x-rays . . . . 12

1.7 Synchrotron development . . . . . . . . . . 13

1.7.1 Energy control . . . . . . ...... 13

1.7.2 Beam extraction.............. 13

1.8 . Photographic pulse height analysis. . . . . . . 13

2. Solid State studies. ............. 14

2.1 Thermal properties of metals at high temperatures . . 14

2.1.1 Thermal conductivity ........... 14

2.1.2 Thermal diffusivity............. 14

2.1.3 Specific heat................ 14

2.1.4 Density.................. 17

2.2 Semiconducting metallic compounds . . . . . . . 17

2.2.1 Magnesium silicide $\left(\mathrm{Mg}_{2} \mathrm{Si}\right) . . . . . . .17$

2.2.2 Magnesium germanide $\left(\mathrm{Mg}_{2} \mathrm{Ge}\right) . . . . . . .18$

2.3 Measurement of magnetic field gradient by the Hall

effect. . . . . . . . . . . . . ... 18

2.4 Electrical conductivity of thin sodium films. . . . . 22

2.5 Mass spectrometric studies of metallic phase transi-

tions.................. 22

2.5.1 Latent heat studies. . . . . . . . . 22

2.6 Superconductivity in rare earth alloys. . . . . . . 22

2.7 Magnetic properties of Ho, Tm and Sm. . . . . . . 23

2.8 Magnetic properties of alloys of Gd and La. . . . . 23

2.9 Remanent magnetism in toroids . . . . . . . . . 23

APPENDIX: LIST OF REPORTS FROM THE ANES LABORATORY. . . . . 25

1. Reports for Cooperating Laboratories . . . . . . 25

2. Papers Published in Scientific Journals. . . . . . 27 


ISC -707 4
SEMI-ANNUAL SUMMARY RESEARCH REPORT IN PHYSICS
For the Period July through December, 1955

This report is prepared from material submitted by the group leaders of the Laboratory

Previous quarterly research reports in this series are:

$$
\begin{aligned}
& \text { ISC }-35 \\
& \text { ISC-4I } \\
& \text { ISC }-56 \\
& \text { ISC }-69 \\
& \text { ISC }-74 \\
& \text { ISC }-76 \\
& \text { ISC }-79 \\
& \text { ISC-113 } \\
& \text { ISC }-130 \\
& \text { ISC }-133 \\
& \text { ISC }-137 \\
& \text { ISC-171 } \\
& \text { ISC }-193 \\
& \text { ISC-220 } \\
& \text { ISC-246 } \\
& \text { ISC-283 } \\
& \text { ISC-301 } \\
& \text { ISC-338 } \\
& \text { ISC-395 } \\
& \text { ISC-422 } \\
& \text { ISC-45I } \\
& \text { ISC-508 } \\
& \text { ISC }-533 \\
& \text { ISC-577 } \\
& \text { ISC }-608 \\
& \text { ISC-645 }
\end{aligned}
$$




\section{PHYSICS}

Under the direction of F。H. Spedding, G.W.Fox, G。C. Danielson, D. E. Hudson, E. N. Jensen, J.M. Keller, J。K.KnIpp, S。Legvold :is

D.J. Zaffarano

C.A. Swenson

Theoretical Physics

1. Magnet1c properties of dysprosium ( $J$. M.Keller)*

We have continued a study of the magnetic properties of dysprosium metal, based on a molecular field model. The apparent existence of a ferromagnetic-antiferromagnetic (F-A) transition at $85^{\circ} \mathrm{K}$ requires that the molecular field coefficients are themselves slowly varying functions of the temperature. Such a model predicts that in a single crystal for a magnetic field applied in the direction of spin orientation, the susceptibility decreases slowly and monotonely as temperature decreases from the Neel point to the F-A transition temperature. For a magnetic fleld perpendicular to the direction of spin orientation, the susceptibility increases continuously as the temperature is lowered, becoming essentially infinite at the F-A transition. (See ISC-645).

According to this theory, the reduction in susceptibility (found experimentally in polycrystalline samples) TF。 Trombe, Compt. rend.236, 591 (1953); J.F. Elliott, S. Leḡvold and F. H. Spedding, Phys. Rev.94, 1143 (1954)7, as the temperature is decreased immediately below the Neel point is attributed to the paraliel susceptibility. This points up the importance of magnetic anisotropy, since if the material were 1sotropic, the spins would always instantaneously rotate into an orientation (nearly) perpendicular to a weak applied magnetic fleld.

We have explored the nature of the magnetic orientations produced by external magnetic fields of arbitrary magnitude and direction, using the molecular field model and including an anisotropy energy proportional to the square of the component of atomic angular momentum in the preferred direction. Competition between the ferro- and antiferromagnetic couplings makes interesting effects occur at magnet1c field strengths considerably lower than is the case for simple antiferromagnetics.

For a field applied perpendicular to the preferred direction, the large perpendicular susceptibility is due to the progressive reorientation of the angular momenta of the different sublattices without change of magnitude, as the external field is made stronger.

* Names indicate group leaders in charge of work. 
At a certain critical field, the angular momenta all become parallel to the applied field, and the crystal becomes essentially a ferromagnetic (or a saturated paramagnet)。

For a field applied nearly parallel to the preferred direction. the Initial (paraliel) susceptibility is small, and due primarily to change in magnitude of the angular momenta of the atoms on the different sublattices. But. When the applied field becomes strong enough to overcome the effects of anisotropy" the angular momenta suddenly rearrange themselves to be nearly perpendicular to the applied field (this phenomenon is known as "spin flop"), and in stronger fields behave essentlally the same as for flelds applied perpendicular to the preferred direction. where is again a change to a ferromagnetic (or saturated paramagnetic) state at still greater applied flelds.

The theory explains qualitatively the magnetization curves of Elliott et al. as follows. In weak external magnetic fields, the magnetization is small because some of the crystaliftes are oriented with their preferred spin direction paraliel to the applied field. When the field strength becomes strong enough to overcome the anisotropy effects, the angular momenta rotate into more effective directions, with a consequent rapid increase in magnetization. The initial susceptiblifty predicted by the theory is somewhat larger, and the rapid increase in magnetization smaller than the experimental observations.: This may be due to the known limitation in any molecular field theory. It may also indicate that the form of anisotropy assumed is inadequate.

2. Electron scattering In transition metals (J。M.Keller)

A report (ISC-687) entitled "Multiband Electrical Conductivity" by John Gibson and $J$. M. Keller is belng distributed.

\section{Abstract}

Scattering amplitudes arising from lattice vibrations are calculated for electrons in a transition metal, with special reference to nickel. The potential in the crystal is treated as a deformable potential, with corrections to adjust the zero of potential and to include effects of the rediatribution of charge during lattice vibration.

The distinction between normal and Umklapp processes is not a sharp one when a deformable potential is assumed. Rather, the scattering gradually takes on more of an Umklapp character as the wave length of the phonon decreases.

The $4 \mathrm{~s}$ electrons are treated in the weak binding and $3 p$ electrons in the strong binding approximation. For s-s scattering, the Umklapp amplitude is larger than normal amplitude by roughly the ratio 
(kinetic energy at the bottom of the band)/(Fermi energy), or about 8 . This makes back-scattering unreasonably likely, and indicates that the method is probably not accurate for large angle scattering. Scattering amplitudes for $s-d$ scattering are of the same order as for $s-s$ scattering in the forward direction. The dependence of $s-d$ amplitude on the various angles is explored.

\section{Experimental Physics}

1. Nuclear Studies

I.1 The decay scheme of $\mathrm{Sc}^{47}$ ( $\mathrm{E} . \mathrm{N}$. Jensen)

A paper entitled "Decay Scheme of $S c^{47 "}$ by $R$ 。 T.Nichols and E. No Jensen, was published. [Phys. Rev., 100, 1407 ( 1955 )]

\section{Abstract}

The radiations of $\mathrm{Sc}^{47}$ have been examined with a scintiliation spectrometer and with an intermediate Image spectrometer operated in conjunction with a scintiliation spectrometer for coincidence spectra. Two beta groups were observed with maximum energy values of $0.596+0.010 \mathrm{Mev}$ and $0.430+0.005 \mathrm{Mev}$ and relative intēnsities of $36 \%$ and $64 \%$ respectively. The log ft values of the beta groups were found to be 6.0 and 5.3 , respectively. One gamma ray was observed having an energy of $0.167 \pm 0.002 \mathrm{Mev}$. The colncidence beta spectrum contalned only the lower energy group. The decay scheme for $\mathrm{Sc}^{47}$ is discussed.

1.2 The decay scheme of $\mathrm{Br}^{82}$ (E.N. Jensen)

The radiations from $\mathrm{Br}^{82}$ have been studied using an intermediateimage colncidence spectrometer, a gamma-gamma coincidence scintillation spectrometer, and gamma-gamma directional correlation equipment. One allowed beta-ray group, having a maximum energy of $444+\mathrm{kev}$, and elght gamma rays were observed. The gamma-ray enerḡies were found to be $545 \pm 2,610 \pm 2,688+2,766 \pm 3$. $81 \% \pm \%, 1,029 \pm 5,1,305 \pm 5$, and $1,469 \pm 7 \mathrm{kev}$. Determinations were made of the relative intensities of the internal conversion electrons, the relative intensities of the gamma rays and the internal conversion coefflcients. Five directional correlation measurements have been performed between various gamma-ray combinations. Unambiguous assignments for the spins and parities of four of the first five excited levels have been made, while the assignment for the remaining level is restricted to two possible values. The propused decay scheme is shown in Fig. 1. Multipole mixing ratios were determined for three of the transitions. The E2 intensity of the 1.30-Mev transition is 15.8 


$$
\mathrm{Br}^{82} \quad \mathrm{kr}^{82}
$$

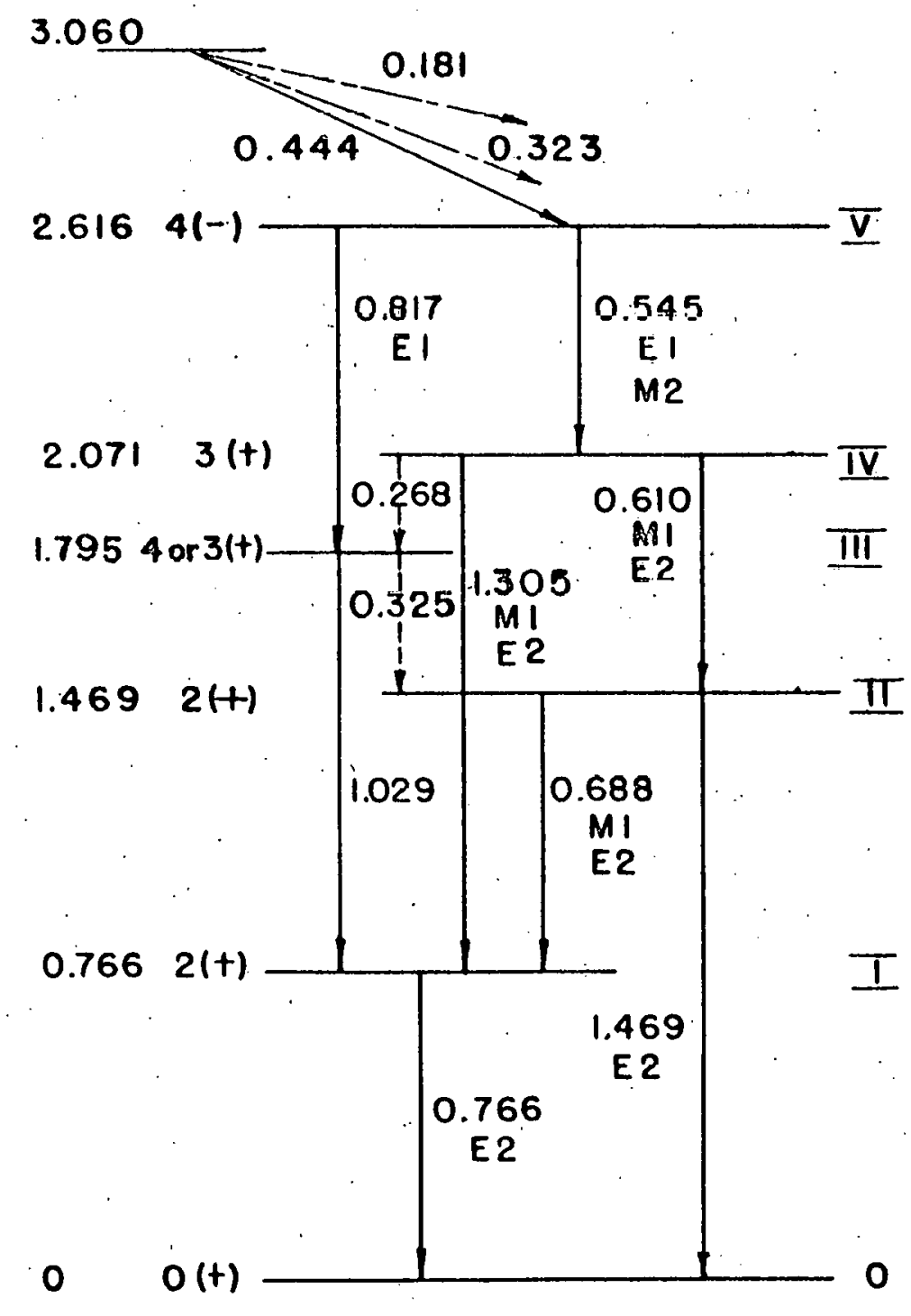

Fig. 1 - Proposed energy level diagram for $\mathrm{Br}^{82}$. The energy levels are given in Mev。 Radiations represented by dashed lines have been reported by Easterday UCRL-2172 (1953)7 and Huddleston and Mitchell ZPhys。Rev。, 88, 1350 (1952)]。 
times that of the MI component, the E2 intensity of the $0.61-M e v$ transition is 5.29 times that of the MI component, and the M2 intensity of the $0.55-\mathrm{Mev}$ transition $1 \mathrm{~s} 2.37$ per cent of the EI component. It appears probable that levels I and II are vibrational levels.

Further details of this study are given in ISC-704.

1.3 Some measurements of beta-gamma directional correlations (E. N. Jensen)

Beta-gamma directional correlation measurements have been made on Re186, Pr142, and La140. The beta detector consisted of a 1 1/8" $x$ 1/8" anthracene crystal mounted on a Lucite pipe sealed to a type 6292 phototube. The gamma detector was a NaI crystal. The source and detectors were mounted in a thin aluminum vacuum chamber.

$$
\operatorname{Re}^{186}
$$

The gamma channel was set to window on the $137 \mathrm{kev}$ photopeak and three measurements of the anisotropy

$$
A \equiv\left[\frac{W\left(180^{\circ}\right)-W\left(90^{\circ}\right)}{W\left(90^{\circ}\right)}\right]
$$

were made with the beta channel set to window as indicated in the tabulated results. All probable errors are statistical.

The Anisotropy A of $\operatorname{Re}^{186}$

Energy Range

$600-1100 \mathrm{kev}$
$600-980 \mathrm{kev}$
$400-600 \mathrm{kev}$
Integral above $400 \mathrm{kev}$
$\dot{A}$

$$
\begin{aligned}
& 0.131 \pm 0.017 \\
& 0.131 \pm 0.014 \\
& 0.070 \pm 0.006 \\
& 0.055 \pm 0.005
\end{aligned}
$$

The above results have been corrected for the finite detector geometry. These results are in agreement with the resuits of Freedman /private communication and Phys. Rev., 98, 214 (1955)7. The source was prepared by evaporating the water from a drop of solution.

$$
\operatorname{Pr}^{142}
$$

Beta-gamma directional correlation measurements were made by setting the gamma analyzer integrally. to pass all radiation above. $1 \mathrm{Mev}$ and the beta analyzer was set to window in the region of 400 - $500 \mathrm{kev}$. The anisotropy of the directional distribution, 
corrected for detector geometry, was found to be $-0.058+0.014$. The source was prepared by evaporating the water from a solution of praseodymium chloride.

$$
\text { Ia } 140
$$

Measurements of the beta-gamma directional correlation between the 1.6-Mev gamma-ray and the 2.15-Mev beta group were made by setting the gamma analyzer. to pass radiation above $900 \mathrm{kev}$ and the beta analyzer to pass betas above $1670 \mathrm{kev}$. The anisotropy of this distribution, corrected for detector geometry, was found to be $0.133 \pm 0.016$.

1.4 Small order effects of beta spectra (E.N. Jensen)

A paper (ISC-658) entitled "Small Order Effects of Beta Spectra", by A。V。Pohm, R。C。Waddell and E. N. Jensen was submitted to Physical Review for publication.

\section{Abstract}

An intermediate-image spectrometer and a thin-lens spectrometer were used to carefully examine the beta spectra of $\mathrm{P} 32, \mathrm{~K}^{42}$, and $\mathrm{As} 76$. The $\mathrm{P} 32$ beta spectrum was examined for a Fierz type deviation and within the experimental exror none was found. The value of "r" describing the magnitude of the Flerz deviation as defined by Davidson and Peasiee was found to be $0.00 \pm 0.03$. The first forbidden transitions with $\Delta I=0$, "yes" of $K^{42}$ and $A s 76$ were examined for deviations from a linear Kurie plot. Within experimental error no deviations were found. From the shape factors calculated by Mahmoud and Konopinski on the basis of an STP combination one would expect deviations for these first forbidden transitions if the best previous estimate of certain parameters are correct. A deviation of the $\mathrm{K}^{42}$ Kurle plot below $500 \mathrm{kev}$ was attributed to an additional beta group.

\subsection{Ionization yields for fission fragments (C. L. Hammer)}

Measurements of the kinetic energy of fission ifragments in gas Ionization chambers have usually been made under the assumption that the average energy per ion pair for fission fragments is the same as that for alpha particles. This assumption has resulted in an energy discrepancy of several per cent for the fission energy. Theoretical work by Knipp and Ling $/ J$. Ko Knipp and R。 C. Iing, Phys. Rev., 82, 30 (1951)7 predicted that the magnitude of the discrepancy should be dependent on the gas used in the lonization chamber. Specifically, the energy should be several per cent higher if the measurements were made in helium rather than in argon. An attempt $\bar{L}$. O. Herwig and G. H. Miller, Phys。Rev., 95, 413 (1954)7 to verify this prediction falled to show any 
difference between helium and argon, although wide variations were found among other gases. An effort has been made to find the theoretically predicted difference in helium and argon, and to discover any other effects which might account for the remaining discrepancy (if any). The gases helium, argon, and a one-tenth per cent argon in helium mixture have been examined.

Natural uranium was fissloned by $D-D$ neutrons and the 1onization was collected in a gridded parallel-plate electron collection chamber. The pulses were sorted and probability versus ionization plots were made. The ionization corresponding to the most probable light fragment and to the most probable heavy fragment were read from these plots. A similar procedure was followed in finding the ionization produced by alpha particles of known. energy from the uranium. The fission energies quoted in Table 1 were found by multiplying the ratio of fission ionization to alpha 1onization by the alpha energy. The gases were continuously purified by a convection purifier containing a calcium-magnesium alloy at $500^{\circ} \mathrm{C}$.

Saturation curves (ionization versus collecting fleld) were taken for the alpha particles and fission fragments. Although the fields were twice those used in the original attempt, a completely flat plateau could not be achieved. Reducing the flelds by onethird lowered the alpha ionization. by three-tenths per cent and the fission ionization (light fragment) by elght-tenths per cent. These slopes were about the same for all three gases. Table 1

Table 1

\begin{tabular}{lcc}
\hline \multicolumn{1}{c}{ Gas } & \multicolumn{2}{c}{ Energy (mev) } \\
\hline Argen & Llght & Heavy \\
Hel1um & 94.2 & 61.1 \\
Hel1um + Argon & 96.6 & 65.3 \\
\end{tabular}

gives the measured energy values. (uncorrested for source thicknese).

The differences in energy found between helium and argon are in line with those expected from theory. It is probable that the original attempt to find a difference falled because sufficient saturation could not be achleved under the flelds obtainable in the chamber at that time.

The possibility of an effect in helium due to metastable states was also examined. One-tenth per cent of argon is 
sufficient to discharge most of the metastable states in hel1um. As the results show, this addition of argon increased the energy significantly. It therefore appears that fission fragments are more efficient in producing metastable states in helium than are alpha particles, thus decreasing the ionization ratio and therefore the measured energy. A pulse rise-time correction, the magnitude of which is now being investigated, should be applied to the energy measured in the mixtures.

1.6 Excltation of isomers by high energy x-rays (C. L. Hammer)

A search for loomerio transitions with half-lives in the microsecond region, which was previously reported, has been extended to include most of the rare earth nucle1. Six of the rare earth nuclei have been found to have long lived states. The results of preliminary measurements are shown in Table 2 .

Table 2

\begin{tabular}{|c|c|c|}
\hline Element & Energy (kev) & $\mathrm{Half}-1 \mathrm{ife}(\mu \mathrm{sec})$ \\
\hline W & $352 \pm 4$ & $14.3 \pm 0.5$ \\
\hline $\mathrm{Lu}$ & 120 & $40-80$ \\
\hline Er & 210 & millisecond region \\
\hline Ho & 300 & milliseoond region \\
\hline $\mathrm{Tb}$ & $\begin{array}{l}\text { only } 45 \text { kev } x \text {-ray } \\
\text { observed }\end{array}$ & millisecond region \\
\hline Nd & 120 & $5-15$ \\
\hline $\operatorname{Pr}$ & 70 & $5-15$ \\
\hline
\end{tabular}

In addition to the rare earth nucle1, turther information concerning the 1somer1c transition in tungsten (ISC-645) has been obtained. Preliminary measurements of the threshold of this reaction, about $10 \mathrm{Mev}$, indicate that the isomeric state is obtained by the emission of a neutron from the parent nucleus, Since only natural tungsten has been used for target material, this means that the isomeric state can be in either $W^{181}$ or W185. W183 has been eliminated because the decay scheme is well known [Dumond et al.s Phys. Rev.s 97, 1007 (1955)] and is not in agreement with the observations reported here. The energy and half-life of this transition, also shown in Table 2, are consistent with that expected from a magnetic quadrupole transition. S. A. Moszkowski, Ch.XIII, Beta and Gamma-ray Spectroscopy, Siegbahn7. Rough measurements of the $K$ shell conversion coefficient 
are in agreement with this assignment /Rose, Goertzel, Perry, ORNL-10237. An extensive search for other $\gamma$-rays following this decay has ylelded negative results thereby determining that the transition goes primarily to the ground state.

Since no $100 \mathrm{kev} \gamma$-ray is observed, the transition from the isomeric state to the flrst rotational level of the nucleus must be more highly forbidden than the transition to the ground state. This observation coupled with the fact that the transition is of the magnetic quadrupole type is not in agreement with the level scheme predicted by Motteleson and Nilsson $\angle \bar{B}$. R. Motteleson and S. G. Nilsson, Phys. Rev。s 99, 1615 (1955)7.

1.7 Synchrotron development (D. J. Zaffarano)

1.7.1 Energy control

Accurate energy control for the synchrotron has been developed and tested. This control utilizes two concentric pickup loops of wire placed above the donut, connected so that the difference voltage is proportional to the time flux change in the vicinity of the equilibrium orbit. This voltage is integrated by means of a chopper stabilized amplifier in a Milier circuit and compared with an absolute D.C. reference. When the signal and reference are equal, a sharp pulse triggers the beam expander circult $\bar{C}_{0} \mathrm{~L}_{0}$ Hammer and A. J. Bureau, Rev. Sci. Instr., 26, 594-598 (1955); C. I. Hammer and A. J. Bureau, Rev. Sci. Instro, 26, 598-600 (1955) 7 and the $x-r a y$ beam is ejected from the donut. In principle, if the area of the plckup coll is known, the R.F. frequency monitored, and the RC of the integrating circuit and bias are known, an absolute calibration of the energy of the machine should be possible.

\section{7 .2 Beam extraction}

Equipment has been installed to allow the use of a larger donut with electrostatic beam deflection for the purpose of: extraction of the internal electron beam of the synchrotron. The external electron beam will provide certain advantages in monitoring, and will permit electron scattering experiments at energies up to $90 \mathrm{Mev}$. Quadrupole lenses have been fabricated for focusing the electron beam.

\subsection{Photographic pulse height analysis (D. Jo.Zaffarano)}

A multichannel pulse-helght analyzer /Hunt, Rhinehart, Weber and Zaffarano, Rev. Sci. Instr., 25, 268 (1954)7 in use at this Laboratory has been simplifled and:a version of the new design has been fabricated. A special, simplified oscilloscope has been constructed for the purpose of presenting information in the form of intensifled pulses which may be recorded photographically. Pulse amplitudes may be recorded at a rate of 104 to 105 per second and analyzed into 200 channels with about $1 \%$ accuracy. This speed, consistent'with good accuracy, makes this analysis system particularly useful with pulsed machines, such as the synchrotron. 


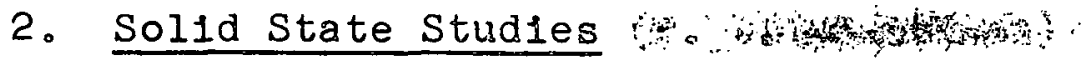

2.1 Thermal properties of metals at high temperatures 2.1.1 Thermal conductivity (G. C. Danielson)

For any metal at any specified temperature $(T)$, the thermal conductivity (K), the thermal diffusivity $(\mathrm{k})$, the specific heat per unit mass (c) and the density (d) are related by the equation $K=k c d$. The object of this experimental program is to determine each of these four quantities to an accuracy of two per cent in the temperature range $20^{\circ} \mathrm{C}$ to $1000^{\circ} \mathrm{C}$.

The thermal conductivity $(K)$ of any metal at any temperature between $100^{\circ} \mathrm{C}$ to $600^{\circ} \mathrm{C}$ can be measured by the apparatus described in ISC-518. The thermal conductivities from $100^{\circ} \mathrm{C}$ to $600^{\circ} \mathrm{C}$ have been measured and reported for nickel (ISC-518), uranium (ISC-533), and zirconium (ISC-577). This static method, which involves the comparison of the temperature gradient in an unknown material to that in a standara material such as Armco iron, gives good results at temperatures under $600^{\circ} \mathrm{C}$. If the temperature range is to be extended above $600^{\circ} \mathrm{C}$, however, major modifications seem to be necessary in order to eliminate electrical leakage between thermocouples.

\subsubsection{Thermal diffusiv1ty}

The thermal diffusivity $(k)$ of any metal at any temperature between $20^{\circ} \mathrm{C}$ and $1000^{\circ} \mathrm{C}$ can be measured by the modifled Angstrom method $\bar{P}$. H. Sidles and G. C. Danielson, J.App. Phys., 25 , 58-66 (1954) described 1n ISC-198. The numerous difficulties encountered in attempting to extend the range from $600^{\circ} \mathrm{C}$ to $1000^{\circ} \mathrm{C}$ have been completely overcome. Hence, our objective (to determine the thermal properties to an accuracy of two per cent in the temperature range $20^{\circ} \mathrm{C}$ to $1000^{\circ} \mathrm{C}$ ) has been attained in the case of thermal diffusivity. An example of the data now possible is shown in Fig. 2. The changes in thermal diffusivity of Armco Iron at the Curie temperature $\left(760^{\circ}-780^{\circ} \mathrm{C}\right)$ and at the $\alpha-\gamma$ phase transformation $\left(910^{\circ} \mathrm{C}\right)$ are clearly measurable. The complicated effects which take place in uranium $\overline{\bar{P}}$. H. Sidles, Phys. Rev., 100, 1256 (1955) 7 at high temperatures are shown in Fig. 3. The possibility of investigating the detalled behavior of thermal diffusivity at phase transformations opens up a new field of research. The success of the rodified Angstrom method depends upon its ability (1) to measure thermal diffusivity at a point in temperature, (rather than determine some average value over a range in temperature), (2) to measure thermal diffusivity with a high degree of reliability and accuracy, and (3) to measure therma diffusivity at exceptionally high temperatures.

\section{1 .3 Specific heat}

The specific heat (c) of any metal at any temperature between $20^{\circ} \mathrm{C}$ and $600^{\circ} \mathrm{C}$ can be measured by the electrical pulse heating method described previously (ISC-645). The method requires considerable modification in ordex to reduce the error to \pm 2 per cent and to extend the temperature range to $1000^{\circ} \mathrm{C}$. The se 


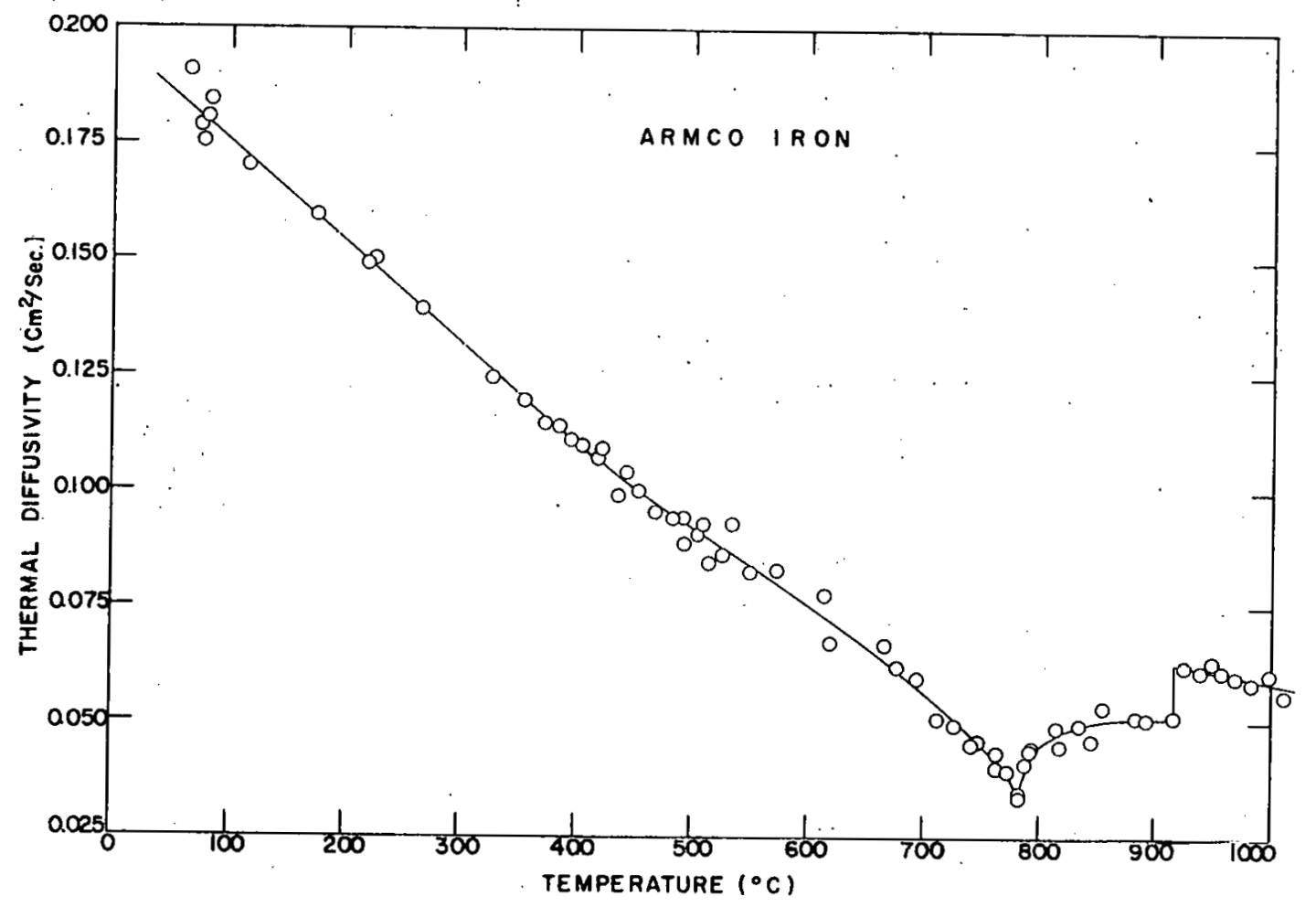

Fig.:2 Thermal diffusivity of Armco iron. 


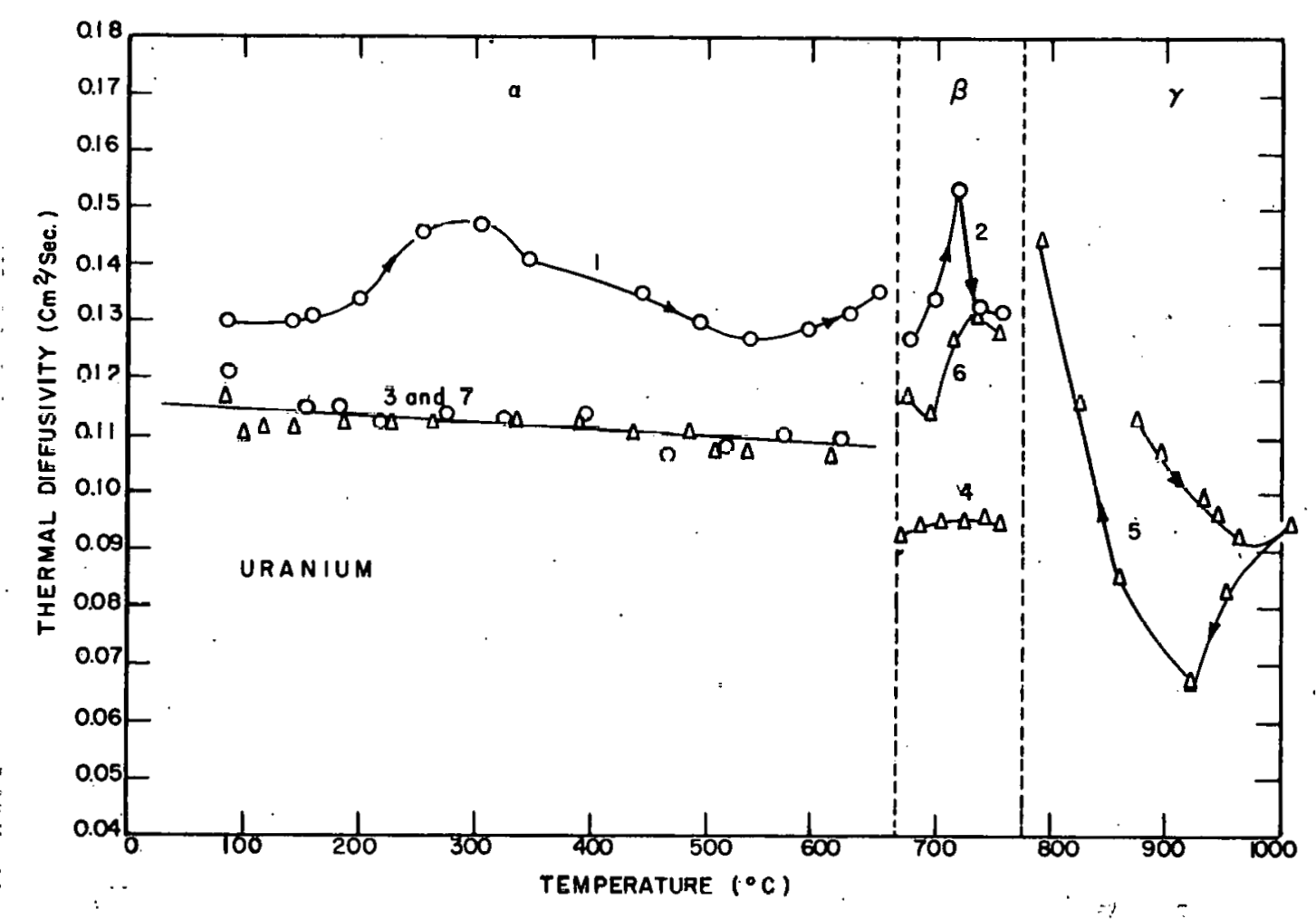

F1g. 3 - Thermal diffusivity of uranium. 
modifications, which seem to be entirely feasible, are nearing completion and include the following: (1) construction of a vacuum furnace in order to adjust the ambient temperature, (2) design of a bridge clrcult so that voltage changes during the pulse can be measured more accurately, and (3) calculation of the heat loss by conduction from the ends of the sample to the electrodes. A report entitled "Measurement of Specific Heat by a Pulse Method", by R. Strittmater and G. C. Danielson is being distributed.

\section{Abstract}

A pulse heating method for measuring the specific heat of metals at all temperatures has been developed. The apparatus will deliver a current pulse of surficient magnitude to heat a fine wloe sample to lis melting temperature in a short time, for example 0.1 second. Under these conditions, the energy losses from the wire are negliglbly small compared with the energy input. By recording simultaneously with a dual beam cathode ray osc1110scope the curpent through and the potential across a sample, one can determine at any instant the power Input and the resistance of the wire. From the resistance of the rise and the results of a preliminary experiment on the resistance-temperature relationship, the temperature can be found. By a single beating pulse $a$ plot of the temperature $a$ a function of time can be made. Since the power input ard the mass of the sample are known, the specific heat, at any temperature within the range of the test, can be calculated. Preliminary results are given for platinum and nickel over the temperature range $25^{\circ} \mathrm{C}$ to $500^{\circ} \mathrm{C}$.

\section{1 .4 Density}

The density (d) of any metal at any temperature between $20^{\circ} \mathrm{C}$ and $600^{\circ} \mathrm{C}$ can be obtained with an error much less than 2 per cent from a measurement of the density at room temperature añd a measurement of the volume expansion coefilcients. The expansion coefficients can be obtained from changes in the unit cell dimensions as determined by $x$-ray diffraction. The high temperature $x$-ray diffraction equipment designed by $P$. Chiott 1

P. Chlotti, Rev. Sc1. Instr., 25, 683-688 (1954)7 could be used for this purpose.

\subsection{Semiconducting metalile compounds ( $G_{\circ} \cdot C$. Danlelson)}

2.2.1 Magnesium silicide ( $\left.\mathrm{Mg}_{2} \mathrm{~S} 1\right)$

The electrical resistivities and Hall coefficients of single crystals of $\mathrm{Mg}_{2} \mathrm{Si}$ have been measured in the temperature range

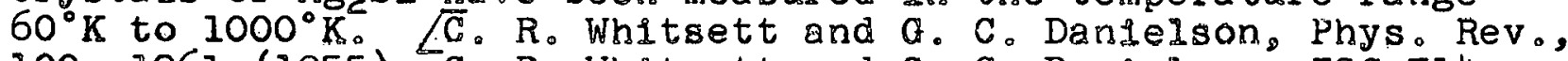
100,1261 (1955): CoR。Whytsett and G。C.Danlelson, ISC-714, (1955)7. Since the Hali coefficients were always negative. electron conduction always predominated over hole conduction 
In these particular single crystals. At $300^{\circ} \mathrm{K}$ the density of electrons from impurity levels was 1017 to 1018 per $\mathrm{cm}^{3}$ and the Hall mobllity was about $200 \mathrm{~cm}^{2} /$ volt-second. Above $300^{\circ} \mathrm{K}$ the temperature dependence of the moblilty in $\mathrm{Mg}_{2} \mathrm{~S} 1$ was given by $9(105) \mathrm{T}-3 / 2 \mathrm{~cm}^{2} /$ volt-second. In the intrinsic region ( $\mathrm{T}>500^{\circ} \mathrm{K}$ ) the resistivity $(\rho)$ was given by the equation $P=A$ exp. $(\Delta \mathrm{E} / 2 \mathrm{kT})$ where $\mathrm{A}=3.2\left(10^{-4}\right) \mathrm{ohm}-\mathrm{cm}$ and $\Delta E=0.48 \mathrm{ev}$. The ratio of the electron mobility to the hole moblilty was estimated to be about 1.3. The effective masses of the electrons and holes were estimated to be 1.8 and 2.0 times the free electron mass.

Since the value for $\Delta E$ is less rather than greater than $\Delta E$ for $\mathrm{MB} 2 \mathrm{Ge}$ (one would expect the order of activation energies to be greatest for $\mathrm{Mg} \mathrm{S}_{1}$ and least for $\mathrm{Mg} \mathrm{Pb}_{\mathrm{Pb}}$ ), these tentative results wili be checked with additional experimental data.

$$
2.2 .2 \text { Magnesium germanide (Mgrae) }
$$

The electrical resistivities and Hall coefficients of single crystals of $\mathrm{Mg} \mathrm{Ge}$ have also been measured in the temperature range $60^{\circ} \mathrm{K}$ to $1000^{\circ} \mathrm{K}$. Again, electron conduction always predominated over hole conduction in these particular single orystals. The density and mobli1ty of the electrons were about 1017 to 1018 per $\mathrm{cm}^{3}$ and $200 \mathrm{~cm}^{2} /$ volt-second as for Mg2Si. In the intrinsic region $\left(T>500^{\circ} \mathrm{K}\right)$ the resistivity ( $P$ ) was given by the equation $\rho=A \exp (\Delta E / 2 \mathrm{kT})$ where $A=1.2(10-4)$ ohm $-\mathrm{cm}$ and $\Delta E=0.64 \mathrm{ev}$.

These tentative results have recently been confirmed by additional data on an additional crystal (3B) cut from the same 1ngot. (see Figs。 4, 5 and 6).

2.3 Measurement of magnet1o field gradient by the Hall effect

(G.C. Danielson)

A report entitled "Measurement of Magnetic Fleld Gradient by the Hall Effect" by $R_{0} D$. Redin and $G$ o $C$. Danielson is being distributed as ISC-685 $\overline{\bar{R}}$ 。 D. Redin and Go C. Danielson, Phys。 Rev., 100, 1252 (1955)

\section{Abstract}

A magnetic field gradient measuring device, which uses the Hall effect in germanium, has been constructed. The field sensitive element is a bar of germanium $1 \mathrm{~mm}$ by $1 \mathrm{~mm}$ by $12 \mathrm{~mm}$ wth two sets of Hall leads attached $2 \mathrm{~mm}$ either side of $1 \mathrm{ts}$ center. One hundred cycle alternating current flows in the long direction of the bar. In a magnetic field two 100 cycle Hall voltages are obtalned. These voltages, which are proportional to the magnetic field strength at two points of the field $4 \mathrm{~mm}$ apart, are subtracted to give an output directly proportional to the magnetic fleld gradient. 
19

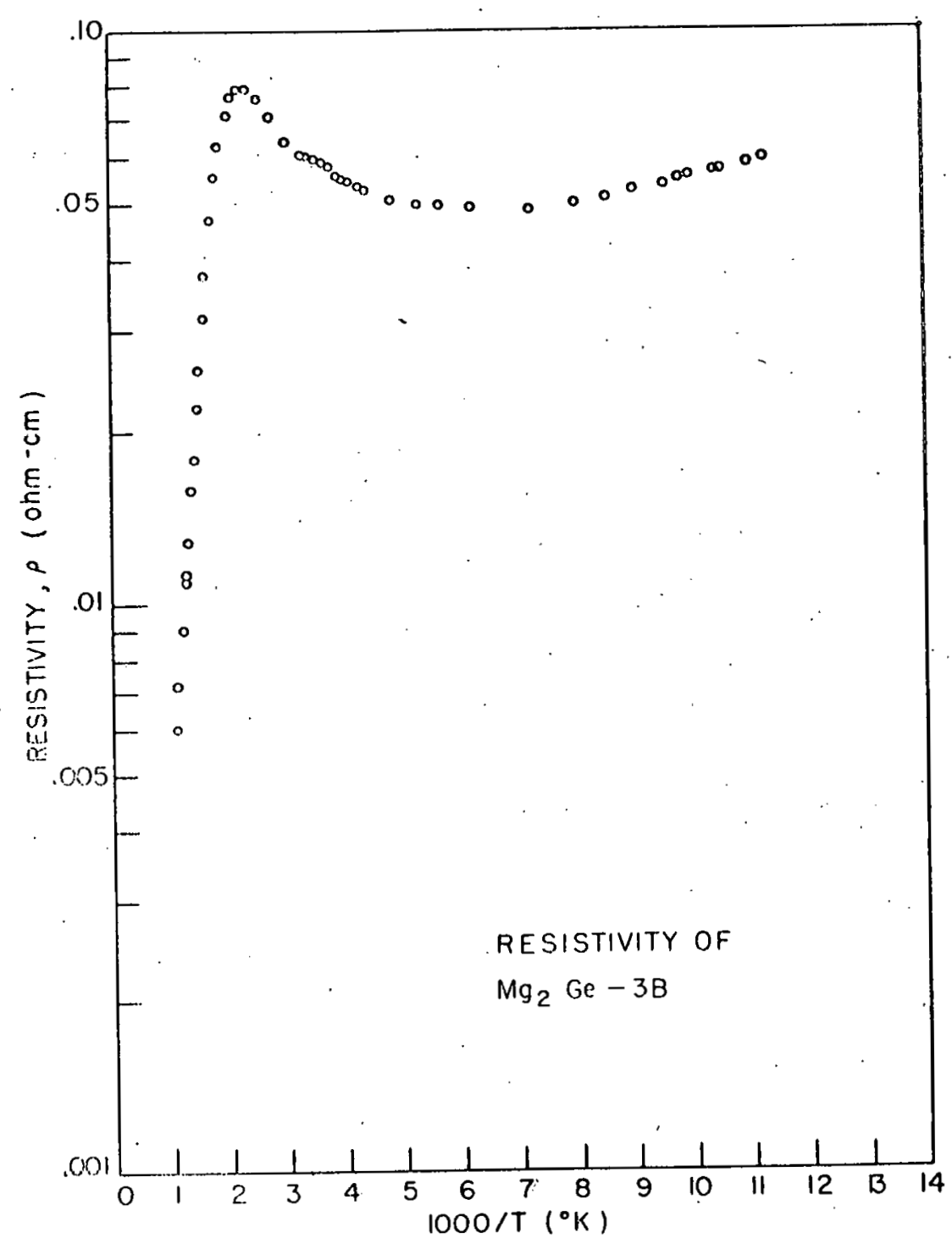

Fig. 4 - Resistivity of $\mathrm{Mg}_{2} \mathrm{Ge}-3 \mathrm{~B}$. 


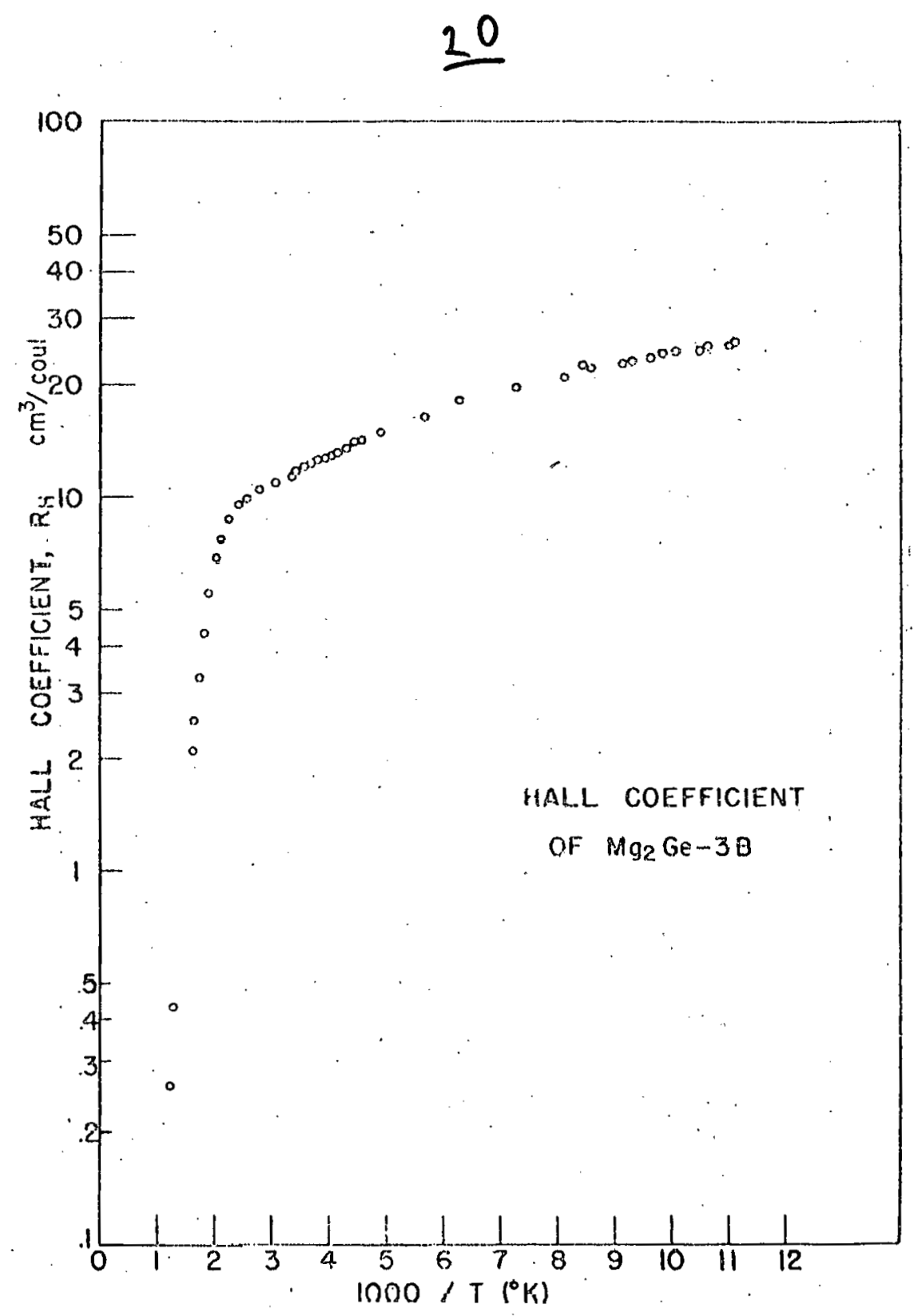

F1g. 5 - Hall coefficient of $\mathrm{Mg}_{2} \mathrm{Ge}-3 \mathrm{~B}$. 


\section{1}

$\therefore$

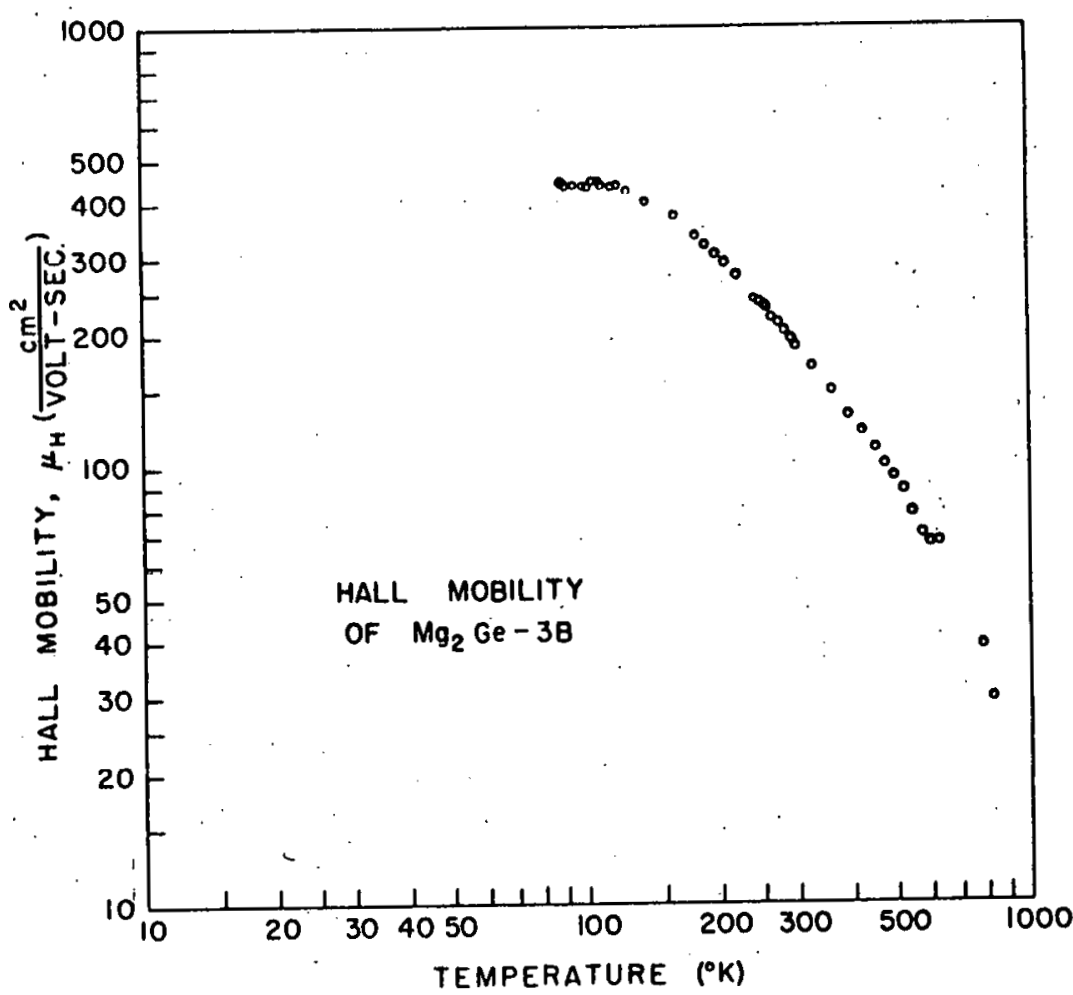

Fig. 6 - Hall mobility of $\mathrm{Mg}_{2} \mathrm{Ge}-3 \mathrm{~B}$. 
The instrument wiII also measure field strengths and relative gradients. The instrument was tested in a calculable magnetic field produced by step pole pieces. Gradients from 5 gauss/1nch to 500 gauss/inch in magnetic flelds below 5000 gauss were measured. The usefulness of the instrument is still uncertain owing to errors caused by excessive field dependence of the gradient voltage.

\section{4 Electrical conductivity of thin sodium films (G.C. Danielson)}

The purpose of this project is to measure the conductivities of thin sodium films as a function of thickness and temperature. Such information would, in principle, determine the density, mean free path, and mobility of the carriers as a function of temperature.

A film of sodium was deposited on a substrate at $102^{\circ} \mathrm{K}$ and in vacuo by emission of sodium atoms from a small hole in an oven. The resistivity was measured as the deposition took plaoe, starting when the film was $177 \AA$ thick and continued until $1 t$ was $446 \AA$ thick. (The number of atoms evaporated was calculated by kinetic theory). The final resistivity at $102^{\circ} \mathrm{K}$ was $3.60\left(10^{-6}\right)$ ohm-cm. After being warmed to $236^{\circ} \mathrm{K}$ and then cooled again to $102^{\circ} \mathrm{K}$, the resistivity was $2.82(10-6)$ ohm-cm. The resistivity of bulk sodium at $102^{\circ} \mathrm{K}$ was $1.04\left(10^{-6}\right)$ ohm-cm.

It was found that no single bulk resistivity and electronic mean free path could be used to fit the data to a Sondheimer plot over the entire range of thicknesses. There is some indication that the film was annealing during deposition. This would explain the observed results. It is hoped that this difficulty can be avoided.

2. 5 Mass spectrometric studies of metallic phase transitions (D. E. Hudson)

2.5.1 Latent heat studies

Previous work in this Laboratory on determination of the heat of. vaporization of aluminum has given results for $\Delta \mathrm{H}$ which were very precise (1.e. high internal consistency) but which were somewhat higher than those quoted in the literature. Our current value for the heat of vaporization for aluminum, which is belleved to be more accurate than any previously reported, is $73.6 \pm 0.5 \mathrm{kcal} / \mathrm{mole}$ at $1300^{\circ} \mathrm{K}$. This reduces to a heat of sublimation of $78.1 \pm 0.5 \mathrm{kcal} / \mathrm{mole}$ at $298^{\circ} \mathrm{K}$ compared to the best previous value of $77.5+1.5 \mathrm{kcal} / \mathrm{mole} /$ Brewer and Searly, J. Am. Chem. Soc.s. 73, 5308 71951)7.

2.6 Superconductivity in rare earth alloys ( $S$. Legvold and F. $H$.

It has been known for some t1me that pure La is a superconductor with a transition temperature of about $5.8^{\circ} \mathrm{K}$. Alloys of Ia with small amounts of $\mathrm{Lu}, \mathrm{Yb}$, and $\mathrm{Y}$ are under study to 
determine the shift in the transition temperature caused by. the fore1gn atoms. A mixture of $10 \% \mathrm{Lu}$ and $90 \% \mathrm{La}$ has been investigated. The transition temperature of this mixture is $3^{\circ} .6^{\circ} \mathrm{K}$ showing that the Lu has a marked effect. It is hoped that a study of a sequence of alloys will permit the determination of the transition temperatures of the pure Lu, Yb, and $Y$ metals . Critical field data (the magnetic field required to destroy superconductivity) will also be determined.

:

2. 7 Magnetic properties of $\mathrm{HO}_{2} \mathrm{Tm}$ and $\mathrm{Sm}$ (S. Legvold and F. H. Spedding)

Holmium metal has been studied and the magnetic susceptibility as a function of temperature exhibits a cusp at $133^{\circ} \mathrm{K}$, which indicates that the metal is apparentiy antiferromagnetic below this temperature. The magnetization curves below $133^{\circ} \mathrm{K}$ and down to $20.4^{\circ} \mathrm{K}$ are similar to those below $175^{\circ} \mathrm{K}$ for dysprosium and $1 t$ appears that holmium will become ferromagnetic just below $20^{\circ} \mathrm{K}$.

In the case of thulium metal there is a cusp in the susceptibility versus temperature curve at $51^{\circ} \mathrm{K}$ with the metal apparently antiferromagnetic in the region: $20^{\circ} \mathrm{K}$ to $51^{\circ} \mathrm{K}$. From the field dependence of the magnetic moment below $40^{\circ} \mathrm{K}$ there is evidence that Tm w1ll become ferromagnetic, but notiuntil the temperature is considerably below $20^{\circ} \mathrm{K}$.

Thullum metal is non-magnetic down to $20.4^{\circ} \mathrm{K}$.

a. 8 Magnet1c properties of alloys of Gd and La (S. Legvold and F.H. Spedding)

Studies of the magnetic properties of alloys of Gd with La were initiated. The addition of La to Gd lowered the paramagnetic Curle temperature. A mixture of $10 \% \mathrm{La}$ in Gd was ferromagnetic below $254^{\circ} \mathrm{K}$. Mixtures of $25 \% \mathrm{La}$ in Gd and $54 \%$ Ia in Gd did not become ferromagnetic down to $20.4^{\circ} \mathrm{K}$. The magnetic behavior of the latter two alloys was certainly not normal. X-ray examinations of the alloys by others in this Laboratory showed the $10 \%$ La in Gd had the Gd structure (hex close-packed) and that the $25 \%$ and $54 \%$ alloys did not have the Gd structure.

2. 9 Remanent magnetism in toroids (S. Legvold)

A report entitled "Remanent Magnet1sm in Toroids" by

P. Hall and S. Legvold was distributed as ISC-630.

\section{Abstract}

The Brookhaven Laboratorles have reported that the remanent magnetism in the Cosmotron magnet decreases with increasing pulse height, and increasing pulse length (BNL-1447). A group at Iowa state College has attempted to duplicate these effects with the simple geometry of a virtually complete toroid. It was found in this case that $B_{\text {rem }}$ is independent of the pulse length, rises and 
approaches a constant value as the pulse helght is increased. These results confirm a previous hypothesis that the unusual behavior of the cosmotron remanent. field is due to the particular configuration of the copper and Iron used in that case, and is not due to inherent properties of iron. 
APPENDIX I: LIST OF REPORTS FROM THE AMES LABORATORY 1. Reports for Cooperating Laboratories

ISC-575 Ames Laboratory Staff. Metallurgy. Quarterly Summary Research Report. Octobrer, November, December, 1954.

ISC-604 F. H. Spedding, J. E. Powell and E. J. Wheelwright. The Stability of the Rare Earth Compiexes with NHyd roxye thyle thylenediaminetriace tic Ac1d.

ISC-605 Ames Laboratory Staff. Engineering. Quarterly Summary Research Report, January, February, March, 1955.

ISC-606 Ames Laboratory Staff. Chemistry. Quarterly Summary Research Report. January, February, March, 1955.

ISC-607 Ames Laboratory Staff. Metallurgy. Quarterly Summary . Research Report. January, February, March, 1955.

ISC-608 Ames Laboratory Staff. Phys1es. Quarterly Sumary Research Report. January, February, March, 1955.

ISC-609 Compiled by P. Chiotti and O. N. Carlson. Hanford Slug Program. Quarterly Summary Research Report. January, February, March, 1955.

ISC-6II F. H. Spedding and JoE. Powell. A Laboratory Method for Separating Nitrogen Isotopes by Ion-Exchange.

ISC-612 A. W. Andresen and G. L. Bridger. Recovery of Uranium from Superphosphates.

ISC-6I7 J. E. Powell and F. H. Spedding. Basic Principles Involved in the Macroseparation of Adjacent Rare Earths from Each Other by Means of Ion-Exchange.

ISC-620 R. D. Kross and V. A. Fassel. The Infrared Spectra of Aromatic Compounds . III: The 1045-1185 $\mathrm{cm}^{-1}$. Vibration in Monosubstituted Benzenes.

ISC-62I R. D. Kross and V. A. Fassel. An Infrared Study of Picric Acid Molecular Complexes: 
ISC-623 I. S. Gray and V. A. Fassel. Emission Spectrometric Determination of Low Percentages of Zirconium in Hafnium.

ISC-625 R. D. Kross, V. A. Fassel and M. Margoshes. The Infrared Spectra of Aromatic Compounds. II.: Evidence Concerning the Interaction of $\pi$-Electrons and $\sigma$-Bond Orbitals in $\mathrm{C}-\mathrm{H}$ Out-of-Plane Bending Vibrations.

ISC-629 R. T. Nichols" and E. N. Jensen. The Decay Scheme of $\mathrm{Sc}^{1} 47$.

ISC-630 P. Hall and S. Legvold. Remanent Magnetism in Toroids.

ISC-632 J. T. Jones, Jr. and J. K. Knipp. Notes on Hyperfragments.

ISO-63'3 E.: M. Laytor, JP., R. D. Kross and V. A. Fassel. A Correlation of Bond Length with Stretching Frequency for $\mathrm{C}-\mathrm{O}$ and $\mathrm{C}-\mathrm{N}$ Systems.

ISC-634 G. H. Beyer, E. I. Koerner and E.H. Olson. Conversion of Zirconium Sulfates to Anhydrous Zirconium Tetrafluoride.

ISC-637 E. Wheelwright and F. H. Spedding. The Use of Chelating Agents in the Separating of the Rare Earths Elements by. Ion-Exchange, Method.

ISC-640 P. Chiotti, P. F' Woemer, H. H. Klepfer, K. J. Gill and R. E. Cutreli. Application of Metal Coatings on Uranium-Summary Report.

ISC-64I Compiled by P. Chiotti and 0. N. Carlson. Hanford Slug Program. Quarterly Summary Research Report. April, May, June, 1955.

ISC-642 Ames Laboratory Staff. Engineering. Quarterly Summary Research Report. April, May, June, 1955:

ISC-643 Ames Laboratory Staff. Chemistry. Quarterly Sumary Research Report. Apr11, May, June, 1955.

ISC-645 Ames Laboratory Staff. Physics. Quarterly Summary Research Report. April, May, June, 1955. 
ISC-656 P. Chiotti, H. H. Klepfer and K. J. Gill. UraniumZinc System.

ISC-661 J. S. Fritz and S. A. Sutton. Titration of Mermit. with Bis(2-Hydroxyethyl) Dithiocarbamate.

ISC-665 M. C. Day and A. F. Voigt. The Molecular Chemistry of Antimony and Tellurium.

2. Papers Published in Scientific Journals

Corbett, J. D. and R. K. McNullan

The Lower Oxidation States of Gallium. I. The GaI -GaI system. J. Am. Chem. Soc. 77, 4217-19 (August, 1955).

Corbett, J. D. and S. von Winbush The Solubility of Some Metals in Their Molten Halides. $\mathrm{J}$. Am. Chem. Soc. 77, 3964-66 (August, 1955).

Day, M. C., G. W. Eakins and A. F. Voigt The Disintegration Schemes of the $\mathrm{Te}^{127}$ and $\mathrm{Te}^{129}$ Ground States. Phys. Rev. 100, 796-8 (November, 1955).

Freeland, M. Q. and J. S. Fritz High Precision Micro Spectrophotometric Analysis with Application to V-Al Alloys. Anal. Chem. 27, 1737-4l (November, 1955)。

Fritz, J. S. and M. Johnson Volumetric Determination of Zirconium. Anal. Chem. 27, 1653-5 (October, 1955).

Fritz, J. S. and S. S. Yamamura Rapid Microtitration of Sulfate. Anal. Chem. 27, 1461-64 (September, 1955).

Hansen, R. S. The Theory of Vibration Jets in Liquids of Variable Surface Tensions. ISC J. of Sc1. 30, 301-11 (November, 1955).

Happe, J. A. and D. S. Martin, Jr. Isotope Exchange of Manganese during the Reaction between Manganese (II) and Permanganate. J. Am. Chem. Soc. $\underline{77}$, 4212-17 (August, 1955).

Herwig; L. O., G. H. Miller and N. G. Utterback Some Characteristics of a Gridded Parallel-Plate Ionization Chamber. Rev. Sci. Instr. 26, 929-36 (October, 1955). 
Hettel.;. H. J. and V.A. Fassel

Determination of Fractional Part. Per Million Amounts of Certain Rare Earths in Zirconium Metal. Ion Exchange. Separation-Spectrographic Determination. Anal. Chem. 27, 1311 (August, 1955).

Jones, J。T., Jr. and J. K. Knipp Notés on Hyperfragments. Muovo Cimeneto 2, 857-9 (October, 1955).

Kniseley, R. N. and V.A. Fassel

A Rotating Step Sector for Use with $A C$ or other Intermittent Spectrographic Light Sources. J. Opt. Soe. 45, 1032-4 (Deocmber, 1355).

Kross, R. D. and V. A. Fasse1

The Infrared spectra of Aromatic Compounds. III.

The 1045-1185 $\mathrm{cm}^{-1}$ Vibration in Monosubstituted Benzenes. J. Am. Chem. Soc. $77,5858-9$ (November, 1955).

Laslett, I. J. and D. J. Zaffarano

Nuclear Research with High Energy X-Rays at Iowa State College. The Science Counselor (September, 1955).

Nichols, R. T. and E. N. Jensen

Decay Scheme of Sc 47. Phys. Rev. 100, 5, 1407-1409 (December, 1955).

Ring, I. S., Jr.

The Photodeuteron/Photoproton Yield from Sulfur. Phys. Kev. घy, 137-8 (July, 1955).

Rundle, $\dot{R}$. E。

The Structure of Ice. J. Phys. Ghem. 59, 680-81

(August, 1955).

Simmons, C. R. and R. S. Hansen

Solvolysis of Hafnium and Zirconium Tetrachlorides in Metryl and Elhyi Alcululs. J. Phys. Ohem. 59; 10723 (Oetober, 1955).

Skochdopole, R. E., M. Griffel, and F. H. Spedding

The Heat Capacity of Erbium from 15-3200K. J. Chem. Phys. 23, 12, 2258-63 (December, 1955).

Spedding, F. H. and J. L. Dye

The Vapor Presoure of Meroury at $250-360^{\circ} \mathrm{C} . . \mathrm{J}$. Phys. Chem. 59, 581-3 (July, 1955).

Spedding, F. H. and J.E. Powell

A Laboratory Method for Separating Nitrogen Isotopes

by Ion-Exchange. J. Am. Chem. Soc. 77, 6125-32

(treember, 1955 ). 
Stone, J. F., D. Kirkham and A. A. Read Soil Moisture Determination by a Portable NeutronScattering Mo1sture Meter. Soll Sc1.Soc。 of Am。Proc。 19, 419-23 (October, 1955).

Wilhelm, H. A. and B. A. Rogers The Physical Metaliurgy of Thorlum. IMD. Spec。 Report Series \#1 (October, 1955). 


$$
1-29
$$

\section{THIS PAGE}

WAS INTENTIONALLY

LEFT BLANK 